\title{
Role of obesity and abdominal shape morphometric features to predict postoperative complications and quality of lymph node dissection of gastrectomy for gastric cancer
}

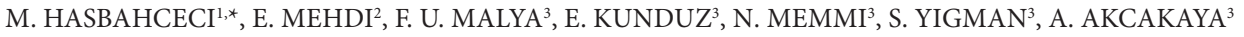 \\ ${ }^{1}$ Clinic of General Surgery, Medical Park Fatih Hospital, Istanbul; ${ }^{2}$ Dept of Radiology Faculty of Medicine and ${ }^{3}$ Dept of General Surgery Faculty \\ of Medicine, Bezmialem Vakif University, Istanbul, Turkey \\ *Correspondence: hasbahceci@yahoo.com
}

Received January 5, 2017 / Accepted April 9, 2017

\begin{abstract}
Obesity and abdominal shape morphometric features have been thought to be independent risk factors for surgical outcomes after gastrectomy.

A total of 113 patients undergoing surgery for primary gastric adenocarcinoma from June 2011 to January 2015 were retrospectively included. Body mass index, visceral fatty area, anterior-posterior abdominal and transverse diameters and depth ratio at levels of the umbilicus, the gastroesophageal junction and the root of the celiac artery were measured or calculated. Patients were grouped according to body mass index $\left(<25.0 \mathrm{~kg} / \mathrm{m}^{2}\right.$ or $\left.\geq 25.0 \mathrm{~kg} / \mathrm{m}^{2}\right)$ or median value of these parameters. Surgical outcomes including postoperative complications, total and metastatic lymph node numbers and their ratio were compared.

There was a significant association between body mass index and abdominal shape indexes. Body mass index and abdominal shape indexes showed no statistical significance on development of complications. But, lymph node numbers and their ratio were negatively affected by depth ratio at the root of the celiac artery.

Our findings showed that gastrectomy with curative intent can be performed safely in patients with higher body mass index and abdominal shape indexes. Therefore, there is no need to perform any change in surgical strategy according to these measurements and calculations.
\end{abstract}

Key words: gastric cancer, gastrectomy, complication, postoperative, lymphatic metastasis, obesity, abdominal, body weights and measures

It has been thought that obesity is a well-known independent risk factor for all-cause mortality [1]. Abdominal operations performed for gastrointestinal tract cancers are technically difficult with substantially increased risk of morbidity and mortality because of the accumulated visceral fat tissues in obese patients [1-4]. Although there have been many studies with regard to the possible relationship between obesity and surgical outcomes from Eastern population, there are a few studies to evaluate the exact impact of obesity on surgical complications and oncologic outcomes of gastric cancer from Western population in which their morphometric features are different from their Eastern counterparts $[1,4,5]$. In addition, there have been also conflicting results about the impact of obesity on perioperative complications [6-8]. Ethnic differences arising from the Eastern and Western countries or individual factors i.e. intra-abdominal fat, subcutaneous fat, and abdominal shape may also have affected this controversy [1].

For the assessment of obesity, body mass index (BMI) has been used for many years. However, it has been believed that $\mathrm{BMI}$ is an imperfect measurement of abnormal or excessive fat accumulation; therefore, it cannot distinguish between muscle and fat accumulation or between central or general obesity, or cannot give information about the localization of visceral fat [ 1 , $9,10]$. Beside BMI, other parameters including waist circumference, hip circumference, visceral fat area (VFA) and anterior to posterior abdominal diameter (APD) have been proposed as alternatives to BMI for assessment of the impact of obesity and fat distribution $[2,9,11,12]$. Generally, these factors have been used to define a new term "abdominal body shape" for preoperative assessment of surgical complications $[1,12,13]$. Depth of surgical sites, poor accessibility to lymph nodes which are deeply 


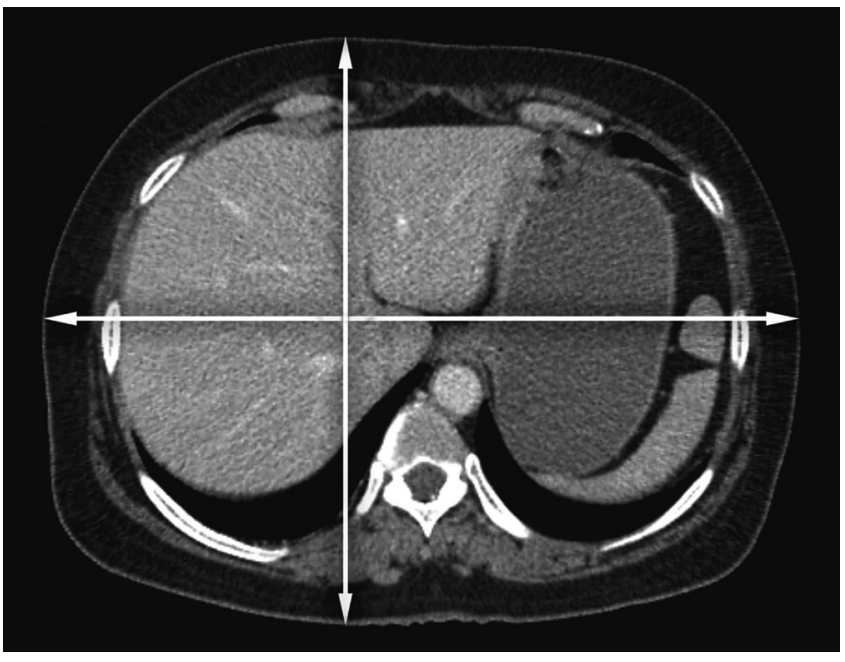

Figure 1. APD-U as the distance between the anterior abdominal skin and the back skin vertically and TD- $U$ as the transverse diameter at the umbilicus.

embedded in adipose tissues around major vessels and technical difficulty to distinguish lymph nodes from surrounding fatty tissue may also predispose obese patients to unsuccessful lymph node dissection during gastrectomy $[2,11,14]$. For this purpose, computed tomography (CT) has been used to measure quantitatively visceral and subcutaneous fat contents and to perform anthropometric measurements including anterior and transverse diameters on specific body parts; thus, they all probably provide more appropriate parameters than BMI to define obesity [10].

In the present study, it was aimed to evaluate the impact of obesity with BMI and VFA, and abdominal shape indexes assessed by anterior and transverse diameters on specific body parts by using CT images on short-term surgical complications and retrieved lymph nodes after gastrectomy.

\section{Patients and methods}

Patients. This retrospective study was approved by the local ethical committee. Informed consent could not be obtained from all patients due to the retrospective design of the study. All procedures were in accordance with the ethical standards of the responsible committee on human experimentation (institutional and national) and with the Helsinki Declaration of 1964 and later versions. The medical records and abdominal CT images of consecutive patients undergoing gastric surgery for primary gastric adenocarcinoma from June 2011 to January 2015 were retrospectively reviewed by using hospital and radiology information systems. There were 171 patients who were operated on for gastric adenocarcinoma. Patients with preoperative CT images taken in the same institution and with distal subtotal or total gastrectomy performed for curative intent were included $(n=139)$. Patients who underwent simultaneous resections except splenectomy, distal pancreatectomy and cholecystectomy for gastric cancer and

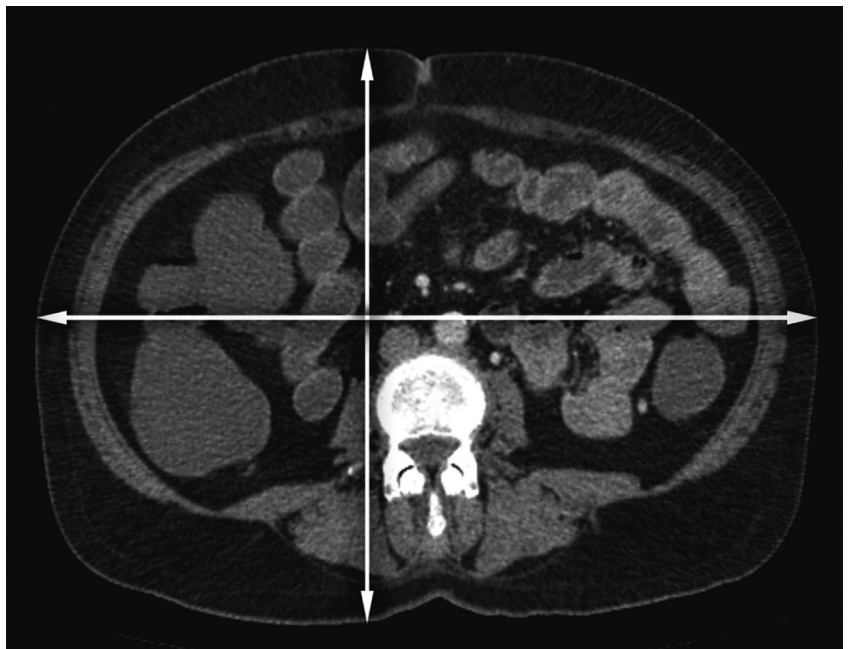

Figure 2. APD-J as the distance between the anterior abdominal skin and the back skin vertically and TD-J as the transverse diameter at the level of the root of gastroesophageal junction.

patients with incomplete medical records and CT images were not included in the study. Patients with neoadjuvant treatment applied for locally advanced gastric adenocarcinoma with bulky lymph nodes $(>3 \mathrm{~cm})$ or clinical $\mathrm{N} 3$ stage $(\mathrm{n}=11)$, type I gastroesophageal junction tumors according to Siewert classification $(n=4)$, surgery for residual gastric cancer $(n=3)$, palliative surgery $(n=8)$ were regarded as the exclusion criteria. Therefore, the remaining 113 patients were included in the study.

Demographic data including age, gender, weight in kilograms and height in meters were recorded preoperatively. BMI was calculated as weight in kilograms divided by the square of height in meters $\left(\mathrm{kg} / \mathrm{m}^{2}\right)$.

Evaluation of CT images. For clinical staging purposes, preoperative $\mathrm{CT}$ images were taken for all histologically proven gastric adenocarcinoma patients to assess the extent of the disease. All CT images were performed within 2-3 weeks before the surgery. A sixty-four channel multi-detector CT (Somatom Sensation 64, Siemens Medical Solutions, Forchheim, Germany) with the following parameters was used: $120 \mathrm{kVp}, 240 \mathrm{mAs}$, 0.828 pitch, $3 \mathrm{~mm}$ slice thickness, supine position with the stomach fully distended with water (a negative contrast medium) 65 sec after contrast medium injection (Ultravist, Schering, Berlin, Germany) at a rate of $3 \mathrm{ml} / \mathrm{s}$, and again in the right decubitus position 3 min after contrast medium injection.

At the level of the gastroesophageal junction, the umbilicus and the root of the celiac artery, APD and transverse diameters (TD) as millimeters ( $\mathrm{mm}$ ) were measured. In addition, VFA as $\mathrm{mm}^{2}$ at the level of the umbilicus (VFA-U) and the root of the celiac artery (VFA-C) were calculated.

$\mathrm{APD}$ at the gastroesophageal junction (APD-J) and the umbilicus (APD-U) were measured as the maximal distance between the anterior abdominal skin and the back skin vertically at supine position (Figure 1 and Figure 2, respectively). 


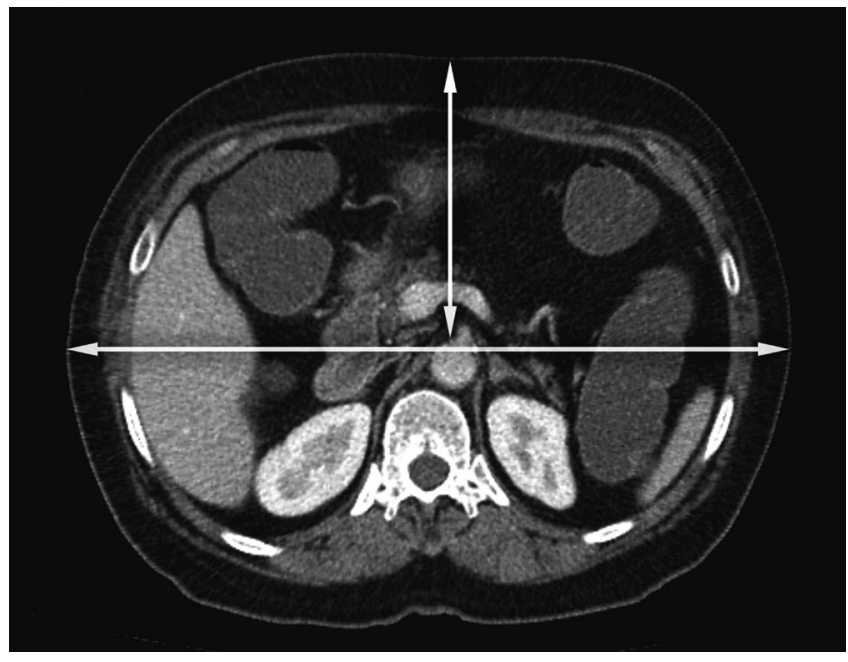

Figure 3. APD-C as the distance between the anterior abdominal skin and the back skin vertically at the level of the root of the celiac artery and TD-C as the transverse diameter of the abdomen at the level of the root of the celiac artery.

APD at the root of the celiac artery (APD-C) was measured as the distance between the anterior abdominal skin and the root of the celiac artery, respectively (Figure 3). TD at the gastroesophageal junction (TD-J), the umbilicus (TD-U) and the root of the celiac artery (TD-U) were defined as the maximal horizontal distances measured at right angles to the APD of the same locations at supine position (Figure 1, Figure 2 and Figure 3, respectively). To calculate the depth ratio at the root of the celiac artery (DR), the following formula was used: $\mathrm{DR}=\mathrm{APD}-\mathrm{C} / \mathrm{TD}-\mathrm{C}$.

For the calculation of VFA, the data were transferred using digital imaging and communications in medicine format to the defined work-station. Fat was defined as any area with Hounsfield intensity between -250 to -50 Hounsfield units. VFA was calculated from the area between the muscular abdominal structures (rectus abdominis, oblique muscles, back muscles). Peri-renal retroperitoneal fat was excluded by drawing the area manually (Figure 2a, b). The work-station semi-automatically calculated VFA inside of the area described above. These measurements and calculations were performed by one of the authors (EM) using an "Image)" software (developed at the National Institutes of Health) and "Measure Stack" plug in (OptiNav Inc.) which were both freely available in the public domain.

Surgery. All surgical procedures were performed by three specified surgeons ( $\mathrm{MH}, \mathrm{AA}, \mathrm{NM})$ on upper gastrointestinal tract cancers. At least two of them were included into each operation.

Patients underwent subtotal or total gastrectomy with D2 lymph node dissection for gastric cancer, as defined by the Japanese Gastric Cancer Association [15]. Open surgical approach was used for all gastric cancer patients. After thorough

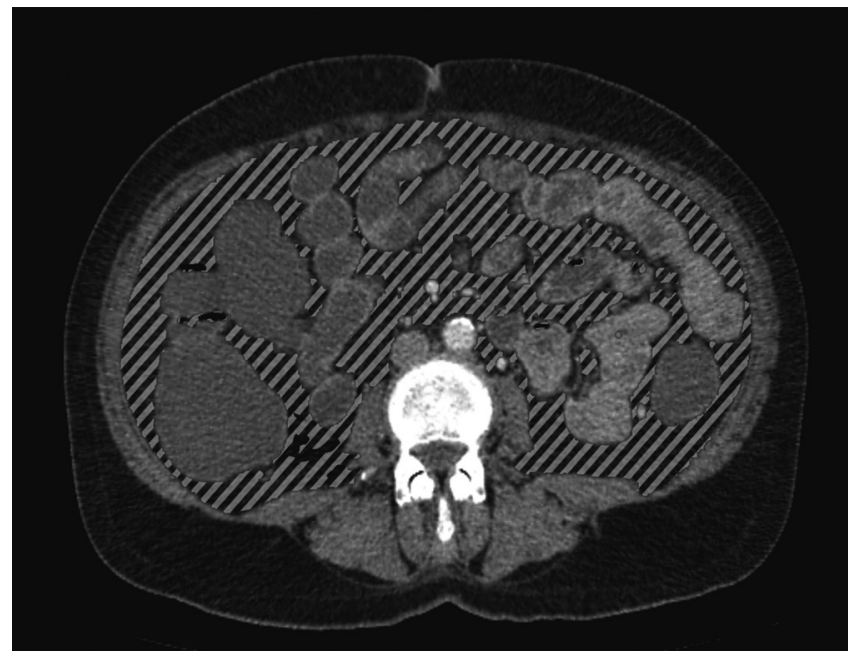

Figure 4. VFA-U (striped area) at the umbilicus.

examination of the peritoneal cavity and the liver revealing the absence of peritoneal dissemination and liver metastasis, respectively, the peritoneal cavity was washed with $200 \mathrm{ml}$ of saline, and at least one third was aspirated for determination of peritoneal washing cytology. After removing the surgical specimen, reconstruction was performed routinely using a Roux-en-Y technique; via a 25-mm circular stapler after total gastrectomy and double layered manual anastomosis after distal subtotal gastrectomy. Antibiotic prophylaxis was performed via three doses at most. One or two drains were applied to all patients and they were removed at the $4^{\text {th }}$ or $5^{\text {th }}$ postoperative day in the absence of any intra-abdominal complication such as anastomotic leakage or intra-abdominal infection.

After the resection of the specimens and the peritoneal washing fluid, they were sent to the pathology laboratory immediately. All pathological examinations were performed in a standard manner by an experienced pathologist who had no knowledge of clinical information including the measurements and calculations. Surgical data with regard to the operation type either distal subtotal or total gastrectomy, intraoperative and postoperative complications (anastomotic leakage, intraabdominal abscess, wound infection, evisceration, clinically significant pancreatic fistula, intraabdominal and anastomotic bleeding, anastomotic stenosis, respiratory and cardiac complications), results of pathologic analysis (maximum diameter, grade, $\mathrm{T}$ stage, $\mathrm{N}$ stage, number of retrieved total and malignant lymph nodes, metastatic to total lymph node ratio and TNM stage) were collected. Metastatic to total lymph node ratio was calculated by dividing metastatic lymph node number to that of total ones. Staging was performed according to TNM staging system by AJCC/UICC [16]. Complication data were collected from the prospectively designed gastric cancer database and early adverse events within 30 days after the surgery were recorded as postoperative complications. Anastomotic leakage was defined as the leakage of the contrast material by 
imaging after the surgery. Intra-abdominal abscess was defined as the intra-abdominal fluid collection identified by imaging in a patient with clinical signs of infection. Clinically significant pancreatic fistula as grade $\mathrm{B}$ and $\mathrm{C}$ was defined according to proposed grading system of the International Group of Pancreatic Surgeons [17]. Anastomotic bleeding was defined as the bleeding necessitating any endoscopic intervention from the anastomotic sites within the first 14 days after the surgery. Anastomotic stenosis was defined as the requirement for endoscopically guided dilation. Wound infection was defined as the presence of purulent discharge from the incision necessitating wound drainage with or without systemic symptoms. Data on postoperative outcome i.e. the length of hospital stay defined as the number of days from the day of the operation until hospital discharge or death was also calculated. Surgical mortality was defined as in-hospital deaths within the first 30 days postoperatively.

Statistical analysis. The potential effects of BMI and these parameters on short-term surgical complications during the postoperative one month, the length of hospital stay and the retrieved lymph node numbers in terms of total and metastatic lymph node numbers and their ratio (metastatic/total lymph node) were investigated.

For this purpose, the patients were grouped according to the categorization of BMI according to World Health Organization cutoff points as follows: Underweight $\left(<18.5 \mathrm{~kg} / \mathrm{m}^{2}\right)$, normal $\left(18.5-24.99 \mathrm{~kg} / \mathrm{m}^{2}\right)$, pre-obese $\left(25.0-29.99 \mathrm{~kg} / \mathrm{m}^{2}\right)$ and obese $\left(>30.0 \mathrm{~kg} / \mathrm{m}^{2}\right)$. However, due to the non-homogeneous distribution between the groups (five, 48, 51 and nine patients in underweight, normal, pre-obese and obese groups, respectively), the study group was divided into two: Group 1 as underweight+normal range, $<25.0 \mathrm{~kg} / \mathrm{m}^{2}$; Group 2 as preobese+obese, $\geq 25.0 \mathrm{~kg} / \mathrm{m}^{2}$. The cut off values in Table 1 were used to define the low- and high- of each abdominal shape index groups. Then, the patients were analyzed according to this grouping based on the median of each abdominal shape index as the cut off value. All statistical analyses were performed using IBM SPSS Statistics ver. 20.0 (IBM Co., Armonk, NY, USA). All continuous values are presented as the mean \pm standard deviation (SD). Categorical variables were expressed as frequencies and percentages. Statistical analysis was conducted by using the Pearson chi-square and Fisher's exact tests for categorical variables and $t$ test and the MannWhitney tests for continuous variables. A $p$ value less than 0.05 was considered statistically significant.

\section{Results}

Demographic and clinico-pathologic data. There were 113 gastric adenocarcinoma patients in the study. The mean age of the patients was $61.7 \pm 11.6$ years with a male to female ratio of 1.57 . The mean BMI was $24.7 \pm 4.4 \mathrm{~kg} / \mathrm{m}^{2}$. Distal subtotal and total gastrectomy with lymph node dissection were performed in 49 (43.4\%) and 64 patients (56.6\%), respectively. Concomitant organ resections were performed in 11 patients

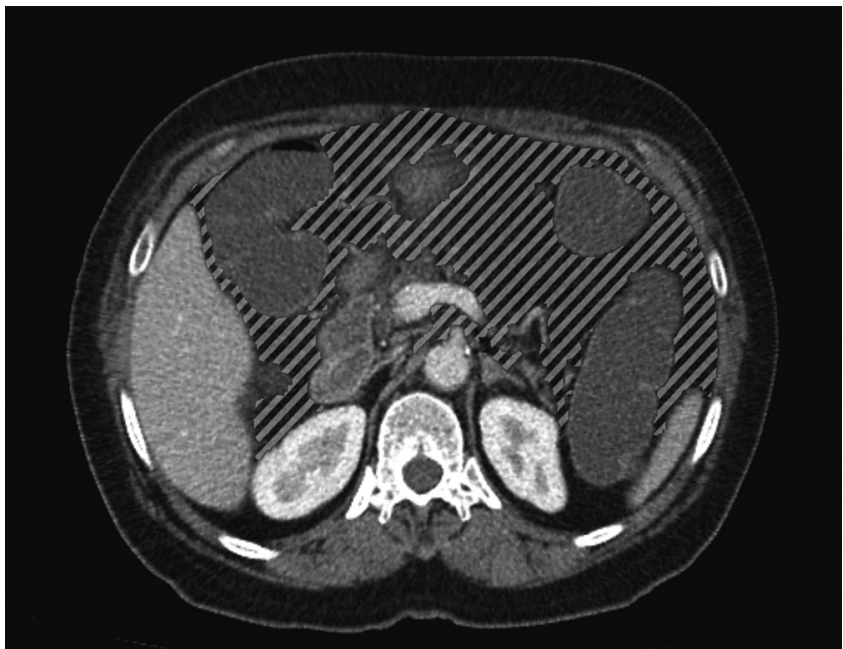

Figure 5. VFA-C (striped area) at the level of the root of the celiac artery (Pay attention to exclusion of retroperitoneal perirenal fatty area).

(9.7\%). Among these, removal of the spleen and the gallbladder were required in 6 and 3 patients, respectively.

Maximum diameter of the tumors was $59.0 \pm 36.8 \mathrm{~mm}$. With regard to the grading of the tumors, undifferentiated and moderately differentiated type tumors were seen in $58(51.3 \%)$ and 43 patients (38.0\%), respectively. Most of the tumors were T4a and T3 in $42(37.2 \%)$ and 35 patients (31.0\%), respectively. Although there was no lymph node metastasis in 23 patients (20.3\%), N3 status was the most common $\mathrm{N}$ stage that was detected in 60 patients (53.1\%). The mean numbers of total retrieved and metastatic lymph nodes were $39.0 \pm 18.6$ and $11.0 \pm 12.3$, respectively, yielding metastatic to total lymph node ratio as $28.0 \pm 27.6$. Based

Table 1. Median and mean values of abdominal shape indexes

\begin{tabular}{lccc}
\hline Feature & Subgroup & Median & Mean \pm SD \\
\hline APD $^{¥}$ & & & \\
& APD-J & 260 & $252 \pm 34$ \\
& APD-U & 233 & $227 \pm 45$ \\
& APD-C & 253 & $246 \pm 36$ \\
TD $^{\ddagger}$ & & & \\
& TD-J & 319 & $316 \pm 33$ \\
& TD-U & 330 & $323 \pm 44$ \\
& TD-C & 318 & $313 \pm 38$ \\
DR $^{*}$ & & & $0.8 \pm 0.14$ \\
VFA $^{\alpha}$ & DR-C & 0.78 & $10232 \pm 7955$ \\
& VFA-U & 11026 & $4828 \pm 4799$ \\
\hline
\end{tabular}

SD: standard deviation; APD: anterior to posterior abdominal diameter; TD: transverse diameter; DR: depth ratio; VFA: visceral fatty area; -J: the gastroesophageal junction, -U: the umbilicus; -C: the celiac artery; $¥ \mathrm{~mm}$; $\mathrm{\alpha}: \mathrm{mm}^{2}$ 
on AJCC staging system, stage III disease was the most common stage that was seen in 50 patients $(44.2 \%)$. The mean length of hospital stay was $9.0 \pm 7.0$ days. There were $53(47 \%)$ and 60 patients (53\%) in Group 1 and 2, respectively. Demographic data of the patients was summarized in Table2. There was no significant difference between the groups with regard to demographic and clinico-pathologic features except BMI and the requirement for concomitant resection (Table 2).
Abdominal shape indexes. The mean and median values for abdominal shape indexes were given in Table 1. The median values of APD-J, APD-C and APD-U were measured as $260 \mathrm{~mm}, 253 \mathrm{~mm}$ and $233 \mathrm{~mm}$ in a descending order, respectively. However, the median values of TD were $330 \mathrm{~mm}, 319 \mathrm{~mm}$ and $318 \mathrm{~mm}$ at the umbilicus, the esophagogastric junction and the root of the celiac artery, respectively. Based on the values at the level of the root of the celiac artery, DR-C was calculated as $0.8 \pm 0.14$. VFA-U

Table 2. Demographic and clinico-pathologic features of the patients

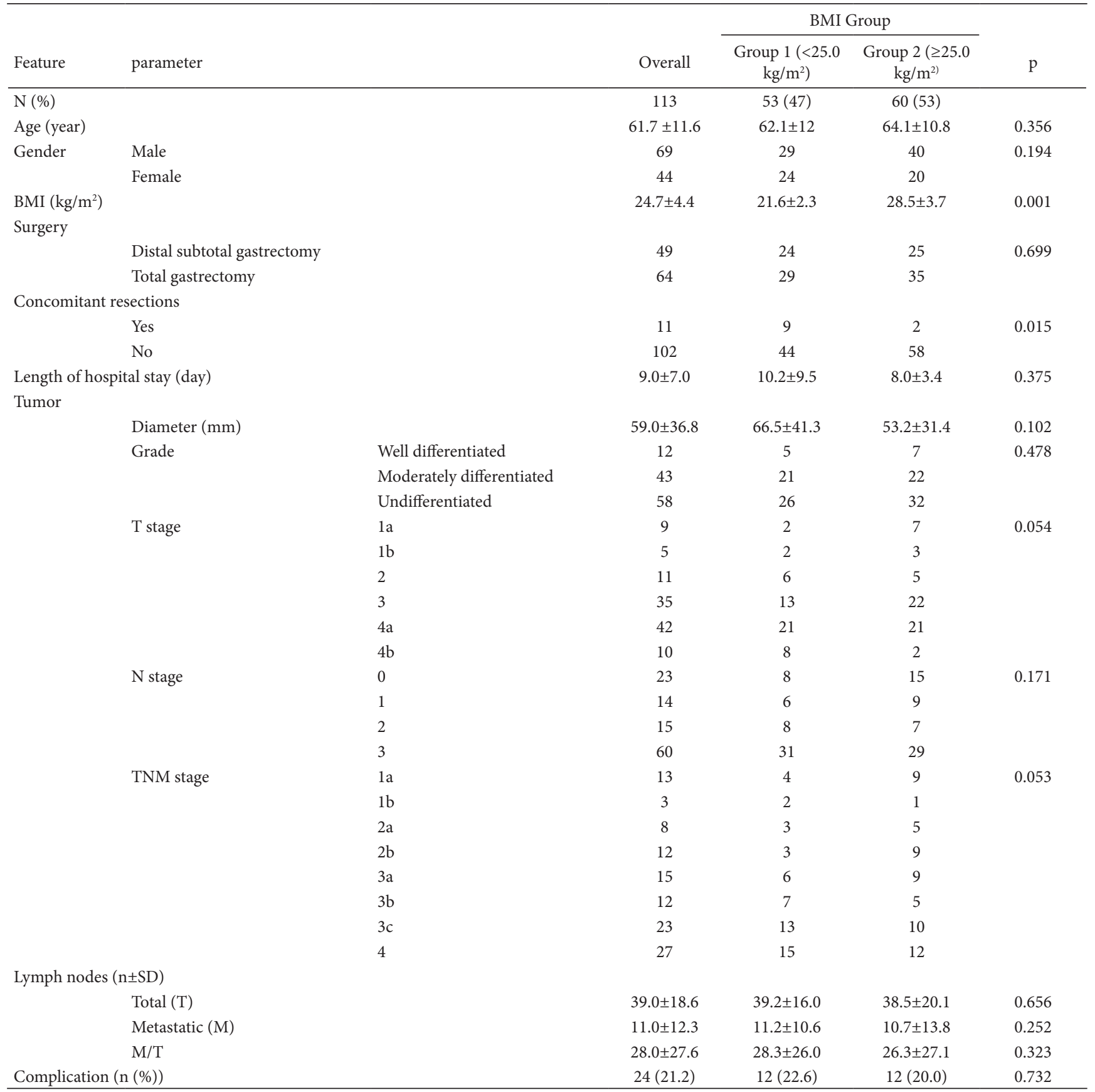


was shown to be greater than VFA-C $\left(10,232 \pm 7,955 \mathrm{~mm}^{2}\right.$ vs. $4,828 \pm 4,799 \mathrm{~mm}^{2}$ ).

There was a significant association between BMI and abdominal shape indexes (Table 3 ). All values of the measurements and calculations including APD, TD, DR-C and VFA were significantly higher in preobese+obese patients $(\geq 25.0 \mathrm{~kg} /$ $\mathrm{m}^{2}$ ) than that of underweight+normal range patients (BMI $\left.<25.0 \mathrm{~kg} / \mathrm{m}^{2}\right)(\mathrm{p}<0.05$ for all $)$.

Complications. Out of 113 patients, there were 30 complications in 24 patients (21.2\%) (Table 4 ). The most common complication was anastomotic leakage in 8 patients. Mortality within 30 days after the operation or within the same admission occurred in 3 patients (2.7\%). There was no significant association between development of complications and demographic, treatment and tumor associated parameters including gender $(\mathrm{p}=0.871)$, concomitant organ resections $(\mathrm{p}=0.171)$, type of gastrectomy $(\mathrm{p}=0.774)$, diameter of the tumor $(\mathrm{p}=0.380)$, T stage $(\mathrm{p}=0.795), \mathrm{N}$ stage $(\mathrm{p}=0.818)$, TNM stage $(\mathrm{p}=0.492)$, total number of lymph nodes $(\mathrm{p}=0.777)$, number of metastatic lymph nodes $(\mathrm{p}=0.919)$ and metastatic to total lymph node ratio $(\mathrm{p}=0.784)$.

Analysis of treatment outcomes based on BMI. Distribution of the complications to the groups based on BMI revealed that $22.6 \%$ (16 complications in 12 patients) and $20.0 \%$ of the patients (14 complications in 12 patients) in groups 1 and 2 had any type of complication, respectively (Table 4). However, BMI showed no statistical significance on development of complications and parameters with regard to total and metastatic lymph node numbers and metastatic to total lymph node ratio (Table 2).

Table 3. Association between abdominal shape indexes and BMI

\begin{tabular}{lcccc}
\hline & & \multicolumn{2}{c}{ BMI Group } & \\
\cline { 3 - 4 } Feature & Subgroup & $\begin{array}{c}\text { Group 1 } \\
\left(<24.9 \mathrm{~kg} / \mathrm{m}^{2}\right)^{\Psi}\end{array}$ & $\begin{array}{c}\text { Group 2 } \\
\left(>25.0 \mathrm{~kg} / \mathrm{m}^{2)}\right.\end{array}$ & $\mathrm{p}$ \\
\hline $\mathrm{N}(\%)$ & $53(47)$ & $60(53)$ & \\
APD $^{\alpha}$ & & & & \\
& APD-J & $236.7 \pm 30.5$ & $274.0 \pm 25.7$ & 0.0001 \\
& APD-U & $207.8 \pm 41.4$ & $255.1 \pm 36.3$ & 0.0001 \\
& APD-C & $231.1 \pm 30.0$ & $271.0 \pm 29.7$ & 0.0001 \\
TD $^{a}$ & & & & \\
& TD-J & $300.0 \pm 28.7$ & $335.2 \pm 25.1$ & 0.0001 \\
& TD-U & $305.2 \pm 40.4$ & $351.9 \pm 36.9$ & 0.0001 \\
& TD-C & $302.6 \pm 27.5$ & $332.8 \pm 37.9$ & 0.0001 \\
DR & & & & \\
VFA $^{\beta}$ & DR-C & $0.77 \pm 0.07$ & $0.83 \pm 0.17$ & 0.023 \\
& & & & \\
& VFA-U & $6474.1 \pm 5911.5$ & $15046.8 \pm 5426.7$ & 0.0001 \\
& VFA-C & $3193.1 \pm 3544.1$ & $8058.5 \pm 5493.3$ & 0.0001 \\
\hline
\end{tabular}

: mean \pm SD; ${ }^{\alpha}: \mathrm{mm} ;{ }^{\beta}: \mathrm{mm}^{2}$

SD: standard deviation; APD: anterior to posterior abdominal diameter; TD: transverse diameter; DR: depth ratio; VFA: visceral fatty area; -J: the gastroesophageal junction, -U: the umbilicus; -C: the celiac artery
Analysis of treatment outcomes based on abdominal shape indexes. If the patients were assigned to one of lowand high- of each abdominal shape index groups according to the median value of each abdominal shape index as the cut off value, DR-C was shown to be significantly associated with total and metastatic lymph node numbers $(\mathrm{p}=0.003$ and $\mathrm{p}=0.021$, respectively) (Table 5). In high-DR-C group, the total and metastatic lymph node numbers were significantly lower than low-DR-C group. Other features have no significant effect on overall surgical complications and parameters with regard to total and metastatic lymph node number and metastatic to total lymph node ratio (Table 5).

Subgroup analysis based on the gender revealed that there were no significant differences with regard to the development of complication, total lymph node number, metastatic lymph node number, and $\mathrm{M} / \mathrm{T}$ ratio between male and female patients. There were also no significant differences with regard to the development of complication and total lymph node number between patients with distal subtotal and total gastrectomy (Table 6). However, the number of metastatic lymph nodes and $\mathrm{M} / \mathrm{T}$ ratio following total gastrectomy was significantly higher than that of distal subtotal gastrectomy ( $\mathrm{p}=0.001$ and $\mathrm{p}=0.001$, respectively)

\section{Discussion}

In this study, the effect of obesity and abdominal shape indexes on short-term surgical complications and retrieved lymph nodes after gastrectomy were studied. In addition to BMI, VFA was used for the measurement of obesity. Additionally, several indexes including APD, TD and DR at multiple locations were used to measure the morphometric features of abdominal body shape. Although there was a close association between obesity and abdominal shape indexes, it could not be possible to show a significant impact of these factors on

Table 4. Postoperative complications

\begin{tabular}{|c|c|c|c|}
\hline \multirow[b]{2}{*}{ Complication } & \multirow[b]{2}{*}{ Overall } & \multicolumn{2}{|c|}{ BMI Group } \\
\hline & & $\begin{array}{c}\text { Group } 1 \\
(\mathrm{BMI}<24.9 \mathrm{~kg} / \\
\left.\mathrm{m}^{2}\right)(\mathrm{n}=53)\end{array}$ & $\begin{array}{c}\text { Group } 2 \\
(\mathrm{BMI}>25.0 \mathrm{~kg} / \\
\left.\mathrm{m}^{2}\right)(\mathrm{n}=60)\end{array}$ \\
\hline Anastomotic leakage & 8 & 4 & 4 \\
\hline Intra-abdominal abscess & 5 & 3 & 2 \\
\hline Wound infection & 4 & 3 & 1 \\
\hline Evisceration & 3 & 1 & 2 \\
\hline $\begin{array}{l}\text { Clinically significant } \\
\text { pancreatic fistula }\end{array}$ & 2 & 0 & 2 \\
\hline Intraabdominal bleeding & 1 & 1 & 0 \\
\hline Anastomotic bleeding & 1 & 1 & 0 \\
\hline Anastomotic stenosis & 1 & 1 & 0 \\
\hline $\begin{array}{l}\text { Respiratory and cardiac } \\
\text { complications }\end{array}$ & 5 & 2 & 3 \\
\hline Total & 30 & 16 & 14 \\
\hline
\end{tabular}

BMI: Body mass index 
the development of complications. However, only DR-C was shown to be significantly associated with total and metastatic lymph node numbers.

It has been generally accepted that obesity substantially increases the risk of morbidity after major abdominal surgery, especially gastrectomy for gastric cancer. Although there have been several studies in which higher BMI is associated with postoperative complications after open gastric cancer surgery $[7,8,13,18-25]$, there have been also many studies with conflicting results due to several factors including study

Table 5. Comparison of treatment outcomes between the groups based on abdominal shape indexes

\begin{tabular}{|c|c|c|c|c|c|c|c|c|c|c|c|}
\hline \multirow[t]{2}{*}{ Feature } & & \multirow[t]{2}{*}{ Sub-group } & \multicolumn{2}{|c|}{ Complication } & \multirow[t]{2}{*}{$\mathrm{p}$} & \multirow{2}{*}{$\begin{array}{c}\text { Total } \\
\text { lymph node } \\
\text { number }^{\beta}\end{array}$} & \multirow[t]{2}{*}{$\mathrm{p}$} & \multirow{2}{*}{$\begin{array}{l}\text { Metastatic } \\
\text { lymph node } \\
\text { number }\end{array}$} & \multirow[t]{2}{*}{$\mathrm{p}$} & \multirow[t]{2}{*}{$\mathrm{M} / \mathrm{Tratio}^{\beta}$} & \multirow[t]{2}{*}{$\mathrm{p}$} \\
\hline & & & No & Yes & & & & & & & \\
\hline \multicolumn{12}{|l|}{$\mathrm{APD}^{q}$} \\
\hline & Low-APD-J & $<260$ & 45 & 11 & 0.82 & $\begin{array}{c}34.5 \\
(27-48)\end{array}$ & 0.506 & $\begin{array}{c}8.5 \\
(1.2-15.5)\end{array}$ & 0.714 & $\begin{array}{c}31.3 \\
(3.1-47.5)\end{array}$ & 0.57 \\
\hline & High-APD-J & $\geq 260$ & 44 & 13 & & $\begin{array}{c}37 \\
(27-52)\end{array}$ & & $\begin{array}{c}6 \\
(1-15.5)\end{array}$ & & $\begin{array}{c}18.2 \\
(3.1-45.9)\end{array}$ & \\
\hline & Low-APD-U & $<233$ & 44 & 12 & 1.000 & $\begin{array}{c}36.5 \\
(27-49.5)\end{array}$ & 0.856 & $\begin{array}{c}6.5 \\
(1.2-14)\end{array}$ & 0.773 & $\begin{array}{c}23 \\
(2.9-44.6)\end{array}$ & 0.74 \\
\hline & High-APD-U & $\geq 233$ & 45 & 12 & & $\begin{array}{c}36 \\
(26-51)\end{array}$ & & $\begin{array}{c}7 \\
(1-17)\end{array}$ & & $\begin{array}{c}18.4 \\
(3.1-46.2)\end{array}$ & \\
\hline & Low-APD-C & $<253$ & 46 & 10 & 0.49 & $\begin{array}{c}36 \\
(27-49.5)\end{array}$ & 0.847 & $\begin{array}{c}9 \\
(1.2-15.5)\end{array}$ & 0.614 & $\begin{array}{c}31.35 \\
(3.1-47.5)\end{array}$ & 0.64 \\
\hline & High-APD-C & $\geq 253$ & 43 & 14 & & $\begin{array}{c}37 \\
(26.5-51)\end{array}$ & & $\begin{array}{c}6 \\
(1-15.5)\end{array}$ & & $\begin{array}{c}17.1 \\
(3.1-45.9)\end{array}$ & \\
\hline \multicolumn{12}{|l|}{$\mathrm{TD}^{¥}$} \\
\hline & Low-TD-J & $<319$ & 46 & 10 & 0.49 & $\begin{array}{c}36 \\
(25-49)\end{array}$ & 0.619 & $\begin{array}{c}8 \\
(1.5-14)\end{array}$ & 0.882 & $\begin{array}{c}26 \\
(4.1-47.2)\end{array}$ & 0.73 \\
\hline & High-TD-J & $\geq 319$ & 43 & 14 & & $\begin{array}{c}37.5 \\
(27-51)\end{array}$ & & $\begin{array}{c}6 \\
(1-18)\end{array}$ & & $\begin{array}{c}18.3 \\
(3.1-45.9)\end{array}$ & \\
\hline & Low-TD-U & $<330$ & 42 & 14 & 0.37 & $\begin{array}{c}36.5 \\
(27-49.5)\end{array}$ & 0.86 & $\begin{array}{c}7 \\
(2-13.8)\end{array}$ & 0.923 & $\begin{array}{c}20.6 \\
(4.5-43.4)\end{array}$ & 0.74 \\
\hline & High-TD-U & $\geq 330$ & 47 & 10 & & $\begin{array}{c}36 \\
(26-51)\end{array}$ & & $\begin{array}{c}7 \\
(1-17.5)\end{array}$ & & $\begin{array}{c}20 \\
(2.8-48.6)\end{array}$ & \\
\hline & Low-TD-C & $<318$ & 45 & 11 & 0.820 & $\begin{array}{c}32 \\
(26-46)\end{array}$ & 0.128 & $\begin{array}{c}8 \\
(2-14)\end{array}$ & 0.618 & $\begin{array}{c}30.4 \\
(4.5-49.1)\end{array}$ & 0.33 \\
\hline & High-TD-C & $\geq 318$ & 44 & 13 & & $\begin{array}{c}38 \\
(29.3-52.3)\end{array}$ & & $\begin{array}{c}6 \\
(1-18)\end{array}$ & & $\begin{array}{c}16.5 \\
(2.9-45.8)\end{array}$ & \\
\hline \multicolumn{12}{|l|}{$\mathrm{DR}$} \\
\hline & Low-DR-C & $<0.78$ & 43 & 13 & 0.82 & $\begin{array}{c}41 \\
(30-54)\end{array}$ & $0.003^{*}$ & $\begin{array}{c}10 \\
(3-23)\end{array}$ & $0.021^{*}$ & $\begin{array}{c}33.3 \\
(8.1-47.9)\end{array}$ & 0.16 \\
\hline & High-DR-C & $\geq 0.78$ & 46 & 11 & & $\begin{array}{c}32 \\
(22-44)\end{array}$ & & $\begin{array}{c}5.5 \\
(0.7-12)\end{array}$ & & $\begin{array}{c}13.6 \\
(1.4-46)\end{array}$ & \\
\hline \multicolumn{12}{|l|}{$\mathrm{VFA}^{\alpha}$} \\
\hline & Low-VFA-U & $<11026$ & 43 & 13 & 0.65 & $\begin{array}{c}37 \\
(27-52)\end{array}$ & 0.443 & $\begin{array}{c}8 \\
(2-19)\end{array}$ & 0.632 & $\begin{array}{c}26 \\
(3.6-47.9)\end{array}$ & 0.79 \\
\hline & High-VFA-U & $\geq 11026$ & 46 & 11 & & $\begin{array}{c}35.5 \\
(26-48.5)\end{array}$ & & $\begin{array}{c}7 \\
(1-15.3)\end{array}$ & & $\begin{array}{c}18.3 \\
(2.9-45.8)\end{array}$ & \\
\hline & Low-VFA-C & $<4492$ & 45 & 11 & 0.82 & $\begin{array}{c}37 \\
(26.3-51.5)\end{array}$ & 0.887 & $\begin{array}{c}8 \\
(1.2-15.5)\end{array}$ & 0.764 & $\begin{array}{c}28.2 \\
(3.8-46.1)\end{array}$ & 0.83 \\
\hline & High-VFA-C & $\geq 4492$ & 44 & 13 & & $\begin{array}{c}36 \\
(27-48)\end{array}$ & & $\begin{array}{c}7 \\
(1-15.5)\end{array}$ & & $\begin{array}{c}18.4 \\
(3.1-46)\end{array}$ & \\
\hline
\end{tabular}

APD: anterior to posterior abdominal diameter; TD: transverse diameter; DR: depth ratio; VFA: visceral fatty area.

-J: the gastroesophageal junction, -U: the umbilicus; -C: the celiac artery

": statistical significance

$\beta$ : median (range); ${ }^{\text {q }}: \mathrm{mm} ;{ }^{a}: \mathrm{mm}^{2}$ 
population, selection criteria of patients and sample size [1, $4,26,27]$. In Chen's study, the overall morbidity mostly comprised of minor complications was higher in high-BMI group than low-BMI or normal-BMI groups [26]. However, low-BMI group suffered serious complications resulting in a higher postoperative mortality rate. Low albumin and hemoglobin levels associated with poor nutritional status was thought to be responsible for this high rate of postoperative serious complications. In Ejaz's study, there were no significant differences in the incidence of perioperative morbidity and postoperative infectious complications [4]. In the present study, any significant difference in postoperative complications between the groups based on BMI has not been shown. In these studies, the number of underweight $\left(\mathrm{BMI}<18.5 \mathrm{~kg} / \mathrm{m}^{2}\right)$ and obese $\left(\mathrm{BMI}>30.0 \mathrm{~kg} / \mathrm{m}^{2}\right)$ patients were limited, and normal and preobese patients comprised more than $75 \%$ of the study groups. In the present study, $42.5 \%$ and $45.1 \%$ of the cases were in normal and pre-obese groups, respectively. This fact was also an important parameter to prevent statistical analysis based on BMI groupings as underweight, normal, pre-obese and obese. Probably due to the non-homogenous distribution, no association between BMI and the development of postoperative complications could be detected. Additionally, most of the BMI values of the patients were detected in relatively narrow range and the patients with extreme BMI values were relatively rare due the nutritional effects of gastric cancer. Therefore, the impact of obesity graded by BMI on short-term outcomes after gastric cancer surgery still remains ill-defined.

Gender has been regarded as an important factor for different types of fat accumulation: visceral fat and subcutaneous fat. It has been thought that abdominal shape is sexually dimorphic, and men accumulate more visceral fat and women accumulate more subcutaneous fat $[3,12]$. However, considering VFA levels, there was no significant difference between male and female patients in the present study. Lee speculated that APD and intraabdominal fat volume are important factors for abdominal wall distensibility in men and the number of retrieved lymph nodes in female patients, respectively, The authors also thought that these factors cause major differences in postoperative morbidity and oncologic outcomes [2]. Wang et al [3] detected a significant association between BMI and other abdominal shape parameters and retrieved lymph nodes only in male patients after laparoscopic gastric surgery. Correlations between surgical outcomes and BMI and other parameters has been found only in male patients in Ojima's study [12]. Therefore, the impact of gender on the outcomes of gastric cancer surgery has not been evaluated in the presence of such conflicting results.

Some authors speculated that VFA is more useful variable than BMI in the assessment of surgical complications and retrieved lymph nodes $[1,11,27]$. It has also been demonstrated that intra-abdominal fatty area measured by CT is the most accurate parameter for assessing the abdominal obesity $[9,28]$. In accordance with our study, researchers also showed a positive correlation between BMI and VFA $[9,26$, 29]. Therefore, it may be recommended the use of VFA as an indicator of abdominal obesity even in patients with a normal BMI. With regard to the abdominal shape-related measures including APD, TD and DR-C, there have been many studies with controversial results focusing on the prediction of postoperative complications or retrieved lymph nodes after gastric cancer surgery $[1-3,11,12,14,29]$. The possible impact of these parameters on laparoscopic gastric cancer surgery has been studied more common than that of the open surgery $[1$, $3,11-14,27]$. In Hiki's study, total fat, subcutaneous fat, VFA and the peritoneum celiac axis distance were shown to be only disruptive for estimated blood loss and numbers of retrieved lymph nodes. In the present study, postoperative surgical complications were not significantly different between the groups based on BMI and abdominal body shape indexes as in Hiki' study [14]. In addition to higher BMI, it has been shown that longer APD-C and DR-C were important factors for prediction of pancreatic fistula $[7,13]$. However, the possible effect of gender or the type of operation either open or laparoscopic has not been controlled in these studies. In Lee's study [2], a significant negative relationship between abdominal shape and the number of retrieved lymph nodes, and higher postoperative complication rate in female patients with higher BMI and SCF has been reported. Increased fat content and larger abdominal shape have been found to be negatively associated with retrieved lymph nodes and operative outcomes only after open gastrectomy [14]. In the present study, only DR-C was

Table 6. Comparison of treatment outcomes between the groups based on gender and type of gastrectomy

\begin{tabular}{|c|c|c|c|c|c|c|c|c|c|c|}
\hline \multicolumn{2}{|l|}{ Feature } & \multicolumn{2}{|c|}{ Complication } & \multirow[t]{2}{*}{$\mathrm{p}$} & \multirow[t]{2}{*}{$\begin{array}{c}\text { Total lymph node } \\
\text { number }^{*}\end{array}$} & \multirow[t]{2}{*}{$\mathrm{p}$} & \multirow[t]{2}{*}{$\begin{array}{c}\text { Metastatic lymph } \\
\text { node number }\end{array}$} & \multirow[t]{2}{*}{$\mathrm{p}$} & \multirow[t]{2}{*}{$\mathrm{M} / \mathrm{T}$ ratio } & \multirow[t]{2}{*}{$\mathrm{p}$} \\
\hline & & No & Yes & & & & & & & \\
\hline \multicolumn{11}{|l|}{ Gender } \\
\hline & Male & 54 & 15 & 0.87 & $39.1 \pm 19.6$ & 0.91 & $9.8 \pm 11.5$ & 0.386 & $24.8 \pm 24.9$ & 0.257 \\
\hline & Female & 35 & 9 & & $38.4 \pm 17.3$ & & $12.7 \pm 13.5$ & & $33.9 \pm 31.0$ & \\
\hline \multirow[t]{2}{*}{ Surgery } & Distal $^{a}$ & 40 & 9 & 0.77 & $37.2 \pm 14.7$ & 0.64 & $6.9 \pm 9.4$ & $0.001^{*}$ & $18.1 \pm 21.1$ & $0.001^{*}$ \\
\hline & $\operatorname{Total}^{\beta}$ & 49 & 14 & & $40.5 \pm 21.2$ & & $14.0 \pm 13.4$ & & $36.2 \pm 29.6$ & \\
\hline
\end{tabular}

a: subtotal gastrectomy; $\beta$ : gastrectomy; ${ }^{\text {* }}$ mean \pm SD; ${ }^{*}$ statistical significance; SD: standard deviation 
significantly related with retrieved lymph node numbers. It may be logical to expect that depth of the celiac trunk may negatively affect the quality of lymph node dissection. But, during D2 lymph node dissection, the surgical area is not restricted with the celiac trunk. Thus, the association of obesity and other abdominal shape related parameters with the development of surgical complications or retrieved lymph nodes after open and laparoscopic gastrectomy is still obscure. Although most of these parameters require specialized software or considerable time for calculations, we believe that preoperative knowledge may help surgeons to prepare an optimum surgical team and equipment. But, the superiority of any of them has not been shown. Therefore, the decision with regard to the use of these parameters should be based on the discretion of the surgeons and availability of the technical facilities.

In studies from Eastern countries exploring the effect of abdominal shape morphometric indexes on gastric surgery, the mean or median values of APD and TD at the umbilicus varied up to $200 \mathrm{~mm}$ and $300 \mathrm{~mm}$, respectively $[2,9,12,13$. However, in the present study, the mean APD and TD at the umbilicus were measured as $233 \mathrm{~mm}$ and $330 \mathrm{~mm}$, respectively. In Yamamoto's study, depth ratio at the level of the celiac artery was calculated as 0.37 , in contrary to the value of 0.8 in the present study [13]. Additionally, DR-C was shown to be a significant factor which negatively affects the total and metastatic lymph node numbers in the present study. Therefore, these comparisons can be used to assess the differences in abdominal anthropometric features originating from ethnicity based on geographical distribution. The lack of positive association of complications and parameters with regard to lymph node dissection except DR- C between patients with higher and lower values of these indexes can also be investigated by future prospective studies.

In previous studies, it has been shown that the retrieved number of lymph nodes were fewer in male patients with higher indexes of obesity or abdominal shape $[2,3,11,21]$. In Bickenbach's collective analysis of gastric cancer patients, increased BMI has been shown to be associated with less lymph node sampling [21]. In Wang's study, a negative correlation found between the numbers of retrieved lymph nodes and APD, TD and BMI after laparoscopy assisted distal gastrectomy [3]. However, Kim's study in which lymph node grouping based on the cut off value of 15 -as either high or low- revealed that the percentages indicating fewer retrieved lymph nodes were not significantly different between each BMI classes and VFA groupings [9]. In accordance with these parameters, it has been shown that there is a negative correlation between VFA and the mean numbers of retrieved lymph nodes in patients operated for gastric cancer [11]. Although it has been thought that a greater APD and a larger intraabdominal fat volume influence the quality of lymph node dissection resulting in inaccurate nodal staging, such correlation was not found in the present study [2]. There was also no significant difference in the number or retrieved lymph nodes and metastatic lymph node ratios between high and low APD and
-TD groups. However, only DR-C has been shown to affect negatively the total and metastatic number of the lymph nodes according to the results of this study. In previous studies, it has been thought that the exposure of surgical area in these patients is thought to be poor due to obesity and higher depth ratios i.e. large APD or TD in laparoscopic gastrectomy, due to the differences with regard to the patients, the surgeons and the surgical techniques originating from the several regions of the World, these findings cannot be generalized. Open, laparoscopic or robotic approach that is going to be used for the surgical treatment of gastric cancer is another important issue in this aspect. In the presence of heterogeneity in relation with the approach and the technique, it is logical to see conflicting results between the studies. However, use of open approach with the same surgical teams may decrease such heterogeneity leading more steady outcomes. However, higher DR-C may cause difficulty especially in open surgery to dissect the lymph nodes in an area with difficult surgical exposure.

Therefore, abdominal morphometric indexes except DR-C may not be important risk factors for the lymph node dissection in the open gastrectomy, contrary to other previous studies $[2,14]$.

It has been speculated that operation time and intraoperative blood loss were higher in patients with high BMI, large APD and TD, and high VFA [12]. Dissection of physiological adhesions and excess fatty tissues around major blood vessels were thought to be responsible for extra time and unexpected bleedings occurring in these patients. However, due to the retrospective design of the study, accurate collection of all these intraoperative parameters could not be possible for performing such analysis.

In the presence of conflicting results on the evaluation of obesity on to the development of complications and the quality of oncologic outcomes, the present study has some important features. In addition to BMI, VFA was also used to evaluate the impact of obesity. Detection of a significant relationship between BMI and VFA enables physicians to use one of both parameters. In literature, there have been several indexes for evaluating the measure the morphometric features of abdominal shape. In the light of these studies, we tried to use several indexes including APD, TD and DR at multiple locations. Although there was no significant difference, these measurements at the level of the esophagogastric junction have been tried for the first time in the present study. Higher DR-C has been shown to be negatively associated with total and metastatic number of the lymph nodes. However, with the use of the standardized technique by the same surgical team, it can be possible to perform gastric cancer surgery with an acceptable outcome even in obese patients with higher abdominal morphometric features based on the results of the present study.

Although our results are contradictory to the other studies in which a close association has been shown between obesity and complications following gastric surgery, a single center experience by experienced and specified surgeons may be an 
important factor with regard to this issue. However, prospective multicenter studies are needed to clarify any institutional bias, if present. Retrospective design of the study and lack of any grading system for assessment of postoperative complications due to incomplete medical data were other limitations. Nutritional status of the patients especially in association with low BMI could not be studied because of the limited number of the cases in this group. Although total number of the cases might be regarded as inadequate considering the presence of only 12 complications in each group, inclusion of more cases with power analysis to determine the minimum number of cases for statistically significant results can lead to more concise conclusions.

In conclusion, our findings showed that gastrectomy with curative intent can be performed safely in patients with higher BMI and abdominal shape indexes. No significant association between development of complications and BMI, VFA, and the other abdominal shape indexes at several locations. Therefore, there is no need to perform any change in surgical strategy according to these measurement and calculations. However, only DR-C was shown to be associated with number of retrieved total and metastatic lymph nodes. Prospective studies are needed to clarify the differences in abdominal anthropometric features of the patients from Eastern and Western countries.

\section{References}

[1] EOM BW, JOO J, YOON HM, RYU KW, KIM YW et al. A body shape index has a good correlation with postoperative complications in gastric cancer surgery. Ann Surg Oncol 2014; 21: 1115-1122. https://doi.org/10.1245/s10434-013-3409-4

[2] LEE JH, PAIK YH, LEE JS, RYU KW, KIM CG et al. Abdominal shape of gastric cancer patients influences short-term surgical outcomes. Ann Surg Oncol 2007; 14: 1288-1294. https://doi. org/10.1245/s10434-006-9235-1

[3] WANG W, AI KX, TAO F, JIN KT, JING YM et al. Impact of Abdominal Shape on Short-Term Surgical Outcome of Laparoscopy-Assisted Distal Gastrectomy for Gastric Cancer. J Gastrointest Surg 2016; 20: 1091-1097. https://doi. org/10.1007/s11605-016-3125-Z

[4] EJAZ A, SPOLVERATO G, KIM Y, POULTSIDES GA, FIELDS RC et al. Impact of body mass index on perioperative outcomes and survival after resection for gastric cancer. J Surg Res 2015; 195: 74-82. https://doi.org/10.1016/j. jss.2014.12.048

[5] CAMARGO MC, FREEDMAN ND, HOLLENBECK AR, ABNET CC, RABKIN CS. Height, weight, and body mass index associations with gastric cancer subsites. Gastric Cancer 2014; 17: 463-468. https://doi.org/10.1007/s10120013-0312-4

[6] YASUNAGA H, HORIGUCHI H, MATSUDA S, FUSHIMI $\mathrm{K}$, HASHIMOTO $\mathrm{H}$ et al. Body mass index and outcomes following gastrointestinal cancer surgery in Japan. Br J Surg 2013; 100: 1335-1343. https://doi.org/10.1002/bjs.9221

[7] NOBUOKA D, GOTOHDA N, KATO Y, TAKAHASHI S, KONISHI $\mathrm{M}$ et al. Influence of excess body weight on the surgical outcomes of total gastrectomy. Surg Today 2011; 41: 928-934. https://doi.org/10.1007/s00595-010-4397-7

[8] KULIG J, SIERZEGA M, KOLODZIEJCZYK P, DADAN J, DREWS $M$ et al. Implications of overweight in gastric cancer: A multicenter study in a Western patient population. Eur J Surg Oncol 2010; 36: 969-976. https://doi.org/10.1016/j. ejso.2010.07.007

[9] KIM JH, CHIN HM, HWANG SS, JUN KH. Impact of intraabdominal fat on surgical outcome and overall survival of patients with gastric cancer. Int J Surg 2014; 12: 346-352. https://doi.org/10.1016/j.ijsu.2014.01.010

[10] LI XT, TANG L, CHEN Y, LI YL, ZHANG XP et al. Visceral and subcutaneous fat as new independent predictive factors of survival in locally advanced gastric carcinoma patients treated with neo-adjuvant chemotherapy. J Cancer Res Clin Oncol 2015; 141: 1237-1247. https://doi.org/10.1007/s00432014-1893-y

[11] GO JE, KIM MC, KIM KH, OH JY, KIM YM. Effect of visceral fat area on outcomes of laparoscopy assisted distal gastrectomy for gastric cancer: subgroup analysis by gender and parameters of obesity. Ann Surg Treat Res 2015; 88: 318-324. https://doi. org/10.4174/astr.2015.88.6.318

[12] OJIMA T, IWAHASHI M, NAKAMORI M, NAKAMURA M, TAKIFUJI $\mathrm{K}$ et al. The impact of abdominal shape index of patients on laparoscopy-assisted distal gastrectomy for early gastric cancer. Langenbecks Arch Surg 2012; 397: 437-445. https://doi.org/10.1007/s00423-011-0883-7

[13] YAMAMOTO N, OSHIMA T, SATO T, MAKINO H, NAGANO Y et al. Upper abdominal body shape is the risk factor for postoperative pancreatic fistula after splenectomy for advanced gastric cancer: a retrospective study. World J Surg Oncol 2008; 6: 109. https://doi.org/10.1186/1477-7819-6-109

[14] HIKI N, FUKUNAGA T, YAMAGUCHI T, OGURA T, MIYATA $S$ et al. Increased fat content and body shape have little effect on the accuracy of lymph node retrieval and blood loss in laparoscopic distal gastrectomy for gastric cancer. J Gastrointest Surg 2009; 13: 626-633. https://doi.org/10.1007/ s11605-008-0768-4

[15] JAPANESE GASTRIC CANCER ASSOCIATION. Japanese gastric cancer treatment guidelines 2010 (ver. 3). Gastric Cancer 2011; 14: 113-123. https://doi.org/10.1007/s10120011-0042-4

[16] MARANO L, BOCCARDI V, BRACCIO B, ESPOSITO G, GRASSIA $M$ et al. Comparison of the 6th and 7th editions of the AJCC/UICC TNM staging system for gastric cancer

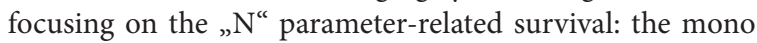
institutional NodUs Italian study. World J Surg Oncol 2015; 13: 215. https://doi.org/10.1186/s12957-015-0633-3

[17] BASSI C, DERVENIS C, BUTTURINI G, FINGERHUT A, YEO C et al. Postoperative pancreatic fistula: an international study group (ISGPF) definition. Surgery 2005; 138: 8-13. https://doi.org/10.1016/j.surg.2005.05.001

[18] DHAR DK, KUBOTA H, TACHIBANA M, KOTOH T, TABARA $\mathrm{H}$ et al. Body mass index determines the success of lymph node dissection and predicts the outcome of gastric carcinoma patients. Oncology 2000; 59: 18-23. https://doi. org/10.1159/000012131 
[19] KODERA Y, ITO S, YAMAMURA Y, MOCHIZUKI Y, FUJIWARA $M$ et al. Obesity and outcome of distal gastrectomy with D2 lymphadenectomy for carcinoma. Hepatogastroenterology 2004; 51: 1225-1228.

[20] INAGAWA S, ADACHI S, ODA T, KAWAMOTO T, KOIKE $\mathrm{N}$, et al. Effect of fat volume on postoperative complications and survival rate after D2 dissection for gastric cancer. Gastric Cancer 2000; 3: 141-144. https://doi.org/10.1007/PL00011708

[21] BICKENBACH KA, DENTON B, GONEN M, BRENNAN MF, COIT DG et al. Impact of obesity on perioperative complications and long-term survival of patients with gastric cancer. Ann Surg Oncol 2013; 20: 780-787. https://doi.org/10.1245/ $\underline{\text { s10434-012-2653-3 }}$

[22] KODERA Y, SASAKO M, YAMAMOTO S, SANO T, NASHIMOTO A et al. Identification of risk factors for the development of complications following extended and superextended lymphadenectomies for gastric cancer. Br J Surg 2005; 92: 1103-1109. https://doi.org/10.1002/bjs.4979

[23] TSUJINAKA T, SASAKO M, YAMAMOTO S, SANO T, KUROKAWA Y et al. Influence of overweight on surgical complications for gastric cancer: results from a randomized control trial comparing D2 and extended para-aortic D3 lymphadenectomy (JCOG9501). Ann Surg Oncol 2007; 14: 355-361. https://doi.org/10.1245/s10434-006-9209-3

[24] PATA G, SOLAINI L, RONCALI S, PASINI M, RAGNI F. Impact of obesity on early surgical and oncologic outcomes after total gastrectomy with "over-D1" lymphadenectomy for gastric cancer. World J Surg 2013; 37: 1072-1081. https://doi. org/10.1007/s00268-013-1942-8

[25] OJIMA T, IWAHASHI M, NAKAMORI M, NAKAMURA M, NAKA $T$ et al. Influence of overweight on patients with gastric cancer after undergoing curative gastrectomy: an analysis of 689 consecutive cases managed by a single center. Arch Surg 2009; 144: 351-358. https://doi.org/10.1001/archsurg.2009.20

[26] CHEN HN, CHEN XZ, ZHANG WH, YANG K, CHEN XL et al. The Impact of Body Mass Index on the Surgical Outcomes of Patients With Gastric Cancer: A 10-Year, Single-Institution Cohort Study. Medicine (Baltimore) 2015; 94: e1769. https:// doi.org/10.1097/MD.0000000000001769

[27] SHIN HJ, SON SY, CUI LH, BYUN C, HUR H et al. Is There any Role of Visceral Fat Area for Predicting Difficulty of Laparoscopic Gastrectomy for Gastric Cancer? J Gastric Cancer 2015; 15: 151-158. https://doi.org/10.5230/jgc.2015.15.3.151

[28] YOSHIKAWA K, SHIMADA M, KURITA N, IWATA T, NISHIOKA $M$ et al. Visceral fat area is superior to body mass index as a predictive factor for risk with laparoscopyassisted gastrectomy for gastric cancer. Surg Endosc 2011; 25: 3825-3830. https://doi.org/10.1007/s00464-011-1798-7

[29] PARK SW, LEE HL, JU YW, JUN DW, LEE OY et al. Inverse association between visceral obesity and lymph node metastasis in gastric cancer. J Gastrointest Surg 2015; 19: 242-250. https://doi.org/10.1007/s11605-014-2682-2 